\title{
Polymyositis with cardiac manifestations and unexpected immunology
}

\author{
I Morrison, A McEntegart, H Capell
}

Ann Rheum Dis 2002;61:1110-1111

$\mathrm{P}$ olymyositis is an inflammatory myopathy of skeletal muscle. Cardiac involvement in the disease was first described in $1899^{1}$ but has only been studied in detail over the past 20 years. About $10-15 \%$ of all patients with polymyositis have a cardiac abnormality as their initial presenting feature, while up to $70 \%$ of all those with polymyositis will have some cardiac involvement diagnosed non-invasively during the course of their illness. ${ }^{2}$ These can manifest either as cardiac failure; electrocardiographic changes, including nonspecific ST changes, and varying forms of AV block; myocarditis; valve disease and myocardial ischaemia in the presence of normal coronary vasculature. ${ }^{3}$

Myasthenia gravis is thought to be an autoimmune disease characterised by the presence of antibodies to the acetylcholine receptor of the motor end plate. Idiopathic forms are rarely associated with polymyositis, ${ }^{4}$ but a much stronger correlation exists in the presence of a thymoma, particularly in those with myocardial involvement, when anti-titin antibodies are usually present. ${ }^{5}$ However, thymoma is often less than $\mathrm{l} \mathrm{mm}$ in size and therefore not visible on computed tomographic (CT) scanning.

We describe a 56 year old woman with polymyositis, who initially presented with myocardial involvement and was also found to have antibodies consistent with myasthenia gravis.

\section{CASE REPORT}

A 56 year old woman was admitted to this hospital for insertion of a permanent pacemaker after an episode of dizziness and collapse, secondary to complete heart block.

She had a past history of anterolateral myocardial infarction 10 months previously for which she received thrombolytic treatment in a district general hospital. Treatment was started with aspirin, atenolol, ramipril, and pravastatin after the infarction. Subsequent coronary angiography was normal. At outpatient follow up five months later, she was found to have a creatine kinase (CK) level of greater than 3000 $\mathrm{U} / \mathrm{l}$ associated with significant leg weakness. Electromyographic (EMG) analysis showed changes consistent with old polio, which had affected the patient as a child. Attempts at muscle biopsy were unsuccessful. A statin-induced myositis was thought likely, and pravastatin was discontinued.

Six months later she presented in complete heart block and at the time of transfer to cardiology in this hospital for pacing, examination showed significant proximal muscle weakness with $3 / 5$ power in both arms, and $2 / 5$ power in the legs; distal muscle power was normal. Neurological examination demonstrated normal sensation but absent knee, bicep and ankle jerks, with bilaterally downgoing plantars.

Investigations showed a CK of $22800 \mathrm{U} / \mathrm{l}$ (CK MB fraction $<0.1)$. The erythrocyte sedimentation rate was mildly raised at $35 \mathrm{~mm} / \mathrm{lst} \mathrm{h}$; thyroid function was normal; and rheumatoid factor, antinuclear antibodies, antineutrophil cytoplasmic antibodies, and viral screens were negative. Echocardiography showed good LV function with trivial MR; ultrasound of the abdomen was normal; and EMG analysis again showed features consistent with previous poliomyelitis, in addition to severe myositis. Magnetic resonance imaging could not be performed because of the pacemaker. A diagnosis of polymyositis was made and treatment was started with $60 \mathrm{mg} /$ day prednisolone and intravenous immunoglobulin. A muscle biopsy, after 13 days of prednisolone, showed an inflammatory infiltrate with myonecrosis consistent with inflammatory myopathy.

Anti-acetylcholine receptor antibodies and anti-titin antibodies were also positive but CT of the thorax showed no evidence of thymoma and single fibre EMG studies were not supportive of a diagnosis of myasthenia gravis.

The patient was discharged after 20 days on $55 \mathrm{mg}$ /day prednisolone with repeat admissions organised for immunoglobulin every six weeks, and neurological review for her possible myasthenia gravis. Upon discharge, she had 4/5 muscle power with a CK of $1113 \mathrm{U} / \mathrm{l}$.

Subsequent follow up two months after her initial admission showed a CK of $<200 \mathrm{U} / \mathrm{l}$ and complete restoration of muscle power. She is currently receiving $35 \mathrm{mg} /$ day prednisolone, reducing by $2.5 \mathrm{mg} / \mathrm{month}$.

\section{DISCUSSION}

Our case demonstrates several of the important cardiac features in polymyositis. The initial infarction, which occurred in the presence of only two significant cardiovascular risk factors (hypertension and hypercholesterolaemia), and the subsequent normal coronary angiography suggest the presence of myocardial ischaemia with normal coronary vasculature as described previously. ${ }^{6}$ It is thought that the ischaemia may be related to small vessel myocardial disease, which would not be evident on angiography. ${ }^{7}$ However, myocardial infarction in the presence of normal coronary vasculature is not uncommon, and alternative explanations in this example include infarction with clot lysis; infarction secondary to coronary artery spasm; or myocarditis.

Fibrosis of the conducting system of the heart, particularly the AV node, has been previously characterised ${ }^{8}$ and might have explained the patient's subsequent presentation in complete heart block. As there was no evidence of significant myocardial ischaemia in this patient (CK MB fraction $<0.1$ and only mildly raised increase in troponin), fibrosis was felt to be the most likely pathological mechanism in this instance.

Arriving at a diagnosis of myasthenia gravis in a patient with muscle inflammation is difficult, as standard investigations such as tensilon tests are inaccurate in the presence of pre-existing muscle weakness, and a negative EMG analysis does not necessarily dismiss the diagnosis. ${ }^{9}$ The presence of old polio in this patient was a further confounding factor. Equally, symptoms may be disguised by both the pre-existing polymyositis and its treatment, as immunosuppression is a well recognised treatment for both. However, antiacetylcholine and anti-titin antibodies are highly specific, ${ }^{10}$ and the association between myasthenia gravis, polymyositis, and cardiac disease, particularly with microscopic thymoma, is well characterised. Although we do not feel we have enough 
evidence to support a diagnosis of myasthenia gravis at present, we have referred this patient for neurological follow up and review.

This case demonstrates several of the cardiac manifestations of polymyositis. It also highlights the possible neurological associations with the disease, and the difficulties in subsequent diagnosis.

\section{Authors' affiliations}

I Morrison, A McEntegart, H Capell, Centre for Rheumatic Disease, Glasgow Royal Infirmary, Scotland, UK

Correspondence to: Dr H Capell, Centre for Rheumatic Disease, Glasgow Royal Infirmary, 84 Castle Street, Glasgow G4 OSF, UK;

hilary.capell@northglasgow.scot.nhs.uk

Accepted 11 April 2002

\section{REFERENCES}

1 Oppenheim H. Zur dermatomyositis. Ber Kil Wochenschr 1899:38:805-7.
2 Gottdiener JS, Sherber HS, Hawley RJ, Engle WK. Cardiac manifestations of polymyositis. Am J Cardiol 1978;41:1131-9.

3 Lie JT. Cardiac manifestations in polymyositis/dermatomyositis: how to get to the heart of the matter. J Rheumatol $1995 ; 22: 809-10$.

4 Miller FM. Current concepts in the idiopathic inflammatory myopathies: polymyositis, dermatomyositis, and related disorders. Pathogenesis. Ann Intern Med 1989:111:150-3.

5 Aarli, Johan A. Inflammatory myopathy in myasthenia gravis. Current Opin Neurol 1998;11:233-4.

6 Lynch PG. Cardiac involvement in chronic polymyositis. Br Heart J $1971 ; 33: 416-19$

7 Denbow CE, Lie JT, Trancredi RG, Bunch TW. Cardiac involvement in polymyositis: a clinicopathologic study of 20 autopsied patients. Arthritis Rhem 1979:22:1088-92.

8 Kehoe RF, Bavernfeind R, Tommaso C, Wyndham C, Rosen KM. Cardiac conduction defects in polymyositis. Electrophysiologic studies in four patients. Ann Intern Med 1981;94:41-3.

9 Oh SJ, Kim DE, Kuruoglu R, Bradley RJ, Dwyer D. Diagnostic sensitivity of the laboratory tests in myasthenia gravis. Muscle Nerve 1992; 15:720-4.

10 Vincent A, Newsom-Davis J. Acetylcholine receptor antibody as a diagnostic test for myasthenia gravis: results in 153 validated cases and 2967 diagnostic assays. J Neurol Neurosurg Psychiatry 1985;48:1246-52.

\section{Eosinophilic fasciitis with multiple myeloma: a new haematological association}

\section{Khanna, A Verity, J M Grossman}

$\mathrm{E}$ osinophilic fasciitis (EF) is characterised by skin induration, hypergammaglobulinaemia, and peripheral eosinophilia. There have been numerous reports of an association of EF with haematological disorders, including monoclonal gammopathy. To our knowledge, we describe the first reported case of an association of EF with multiple myeloma (MM).

\section{CASE REPORT}

A 48 year old white woman presented for evaluation of a 12 month history of progressive increasing skin thickness and tightening and recurrent falls. The patient was in her usual state of health until one year before admission when she noticed increased skin pigmentation with diffuse skin thickening, initially on the thighs but progressing to her abdomen and arms. She denied any Raynaud's phenomenon. On examination, the vital signs were normal. Examination was significant for skin thickening and induration of the thighs and arms. There was minimal sclerodactyly and no digital ulcers, scars or synovitis. No nailfold capillary abnormality was noticed. The oral aperture was mildly decreased with no evidence of telangiectasias. There were bilateral flexion contractures of the knees and the elbows. Results of chest, heart, and abdominal examinations were within normal limits. Neurological examination was significant for proximal muscle weakness, $4 / 5$ in the arms and $3+/ 5$ in the legs. Laboratory data showed normocytic normochromic anaemia. Renal panel and urine analysis results were normal. The patient had a serum albumin of $28 \mathrm{~g} / \mathrm{l}$ with serum calcium of $2.70 \mathrm{mmol} / \mathrm{l}$. Her creatine kinase was $28 \mathrm{U} / \mathrm{l}$ and erythrocyte sedimentation rate (Westergren) $>100 \mathrm{~mm} / \mathrm{lst}$ h. She had a negative antinuclear antibody test and negative antibodies to smith, ribonucleoprotein, and Scl-70. A lumbar sacral spine $x$ ray examination for back pain showed diffuse osteoporosis with multiple wedge fractures. Investigation for secondary osteoporosis included serum and urine electrophoresis, which showed an IgG $\lambda$ monoclonal protein on immunofixation. Serum IgG was $36.00 \mathrm{~g} / \mathrm{l}$ (normal 6.87-16.30) with other immunoglobulins being low normal. A bone marrow biopsy and aspiration was performed which disclosed $25 \%$ plasma cells with immunohistochemistry showing increased numbers of $\lambda$ light chain positive plasma cells and normal chromosomal analysis. This was consistent with $\operatorname{IgG} \lambda$ multiple myeloma.

Full thickness skin, fascia, and muscle biopsy specimens were obtained. The skin biopsy showed evidence of sclerodermatous changes, in which minor epidermal atrophy was associated with modest diffuse hyalinised collagenosis of the dermis. The superficial dermis showed microvascular endothelial swelling, punctate haemosiderosis, and a minimal lymphocytic infiltrate, which contained numerous eosinophils. Mucicarmine and Alcian blue stains were negative. Sections demonstrating fascia and muscle showed a homogeneous collagenosis throughout the fascia, which contained small focal residual islands of perivascular lymphocytosis (fig 1). Congo red reactions were negative for amyloid. Histologically, this was most consistent with eosinophilic fasciitis. The patient was treated with high dose dexamethasone and pamidronate for her MM with mild improvement of her skin induration on two month follow up. The patient, unfortunately, died suddenly at a rehabilitation centre after three months of treatment.

\section{DISCUSSION}

Painful swelling and induration of the skin and underlying soft tissues of the arms and legs clinically characterise EF, first described by Shulman in 1974. ${ }^{1}$ Haematological associations are well described with EF, and have evoked most interest and 


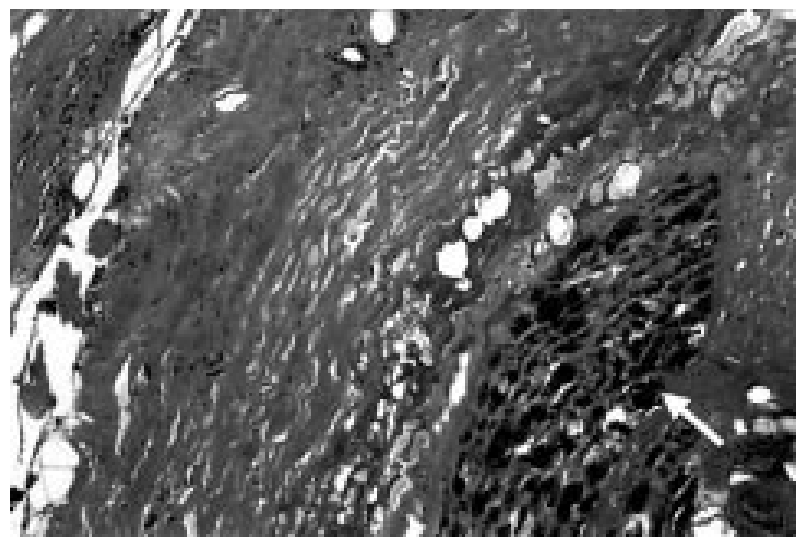

Figure 1 A thickened, hyalinised amorphous tissue containing small chronic inflammatory foci replaces the fascia. The fascial-epimysial interface is replaced by dense collagen inducing compressional atrophy of adjacent muscle bundles (arrow) $(\times 80)$.

concern. EF has been reported with anaemia and thrombocytopenia, pancytopenia, haemolytic anaemia, lymphadenopathy, and pernicious anaemia. ${ }^{2-5}$ Haematological malignancies that have been associated with EF include Hodgkin's disease, lymphoproliferative disorder, angioimmunoblastic lymphadenopathy, peripheral $\mathrm{T}$ cell lymphoma and, possibly, acute myeloid leukaemia, acute myelomonocytic leukaemia, and myeloproliferative disorder; each of the last three conditions have been seen in one case of $\mathrm{EF}^{4-6}$ Whereas hypergammaglobulinaemia is a well described feature of EF, monoclonal gammopathy has only been reported twice. ${ }^{78}$

We present the first case report of IgG $\lambda$ MM associated with EF. The presence of monoclonal gammopathy can also be seen with scleroderma (SSc) like skin diseases including scleromyxoedema and scleredema, ${ }^{10}$ but the pathogenesis of these diseases is still largely unknown. Sera from patients with scleredema and MM have been shown to stimulate collagen production, both in the normal fibroblasts ${ }^{11}$ and in the autologous cell cultures, ${ }^{11}$ suggesting that serum factors produced by the myeloma cells might have a role in the development of dermal thickening. Also, treatment of MM improves the skin disease. ${ }^{11}$ However, in our patient, the skin was not studded with waxy papules, as seen with scleromyxoedema and the skin biopsy was negative for mucopolysaccharide deposition (negative Alcian blue stain). MM has also been seen in two patients with $\mathrm{SSc}^{3}$ and a review of the natural history of monoclonal gammopathy in 241 patients showed that $6 \%$ had SSc and other autoimmune diseases, but no EF. ${ }^{12}$ Furthermore, the two conditions have some additional features in common. Certain cytokine abnormalities are seen in both illnesses. Interleukin $6^{13}$ and transforming growth factor $\beta$ are thought to have an important role in both conditions. These findings suggest that certain serum factors, both known and yet to be elucidated, might have contributed to the association of EF with MM.

Our case demonstrates the diverse and serious haematological manifestations that can occur with EF. Rheumatologists should have a high degree of awareness of MM in a patient with EF who presents with monoclonal gammopathy, as the diagnosis has significant therapeutic implications.

\section{Authors' affiliations}

D Khanna, J M Grossman, Division of Rheumatology, Department of Medicine, UCLA School of Medicine, Los Angeles, CA 90095-1670, USA

A Verity, Division of Neuropathology, Department of Neurology, UCLA School of Medicine, Los Angeles, CA 90095-1670, USA

Correspondence to: Dr D Khanna, Division of Rheumatology, UCLA School of Medicine, 1000 Veteran Avenue, Room 32-59, Rehabilitation building, Los Angeles, CA 90095-1670, USA; khanna72@yahoo.com

Accepted 8 May 2002

\section{REFERENCES}

1 Shulman LE. Diffuse fasciitis with hypergammaglobulinemia and eosinophilia. A new syndrome [abstract]? J Rheumatol 1974;1/suppl 1):46.

2 Lakhanpal S, Ginsburg WW, Michet CJ, Doyle JA, Moore SB. Eosinophilic fasciitis: Clinical spectrum and therapeutic response in 52 cases. Semin Arthritis Rheum 1988;17:221-31.

3 Doyle JA, Connolly SM, Hoagland HC. Hematologic disease in scleroderma syndromes. Acta Derm Venereol (Stockh) 1985;65:521-5.

4 Doyle JA. Eosinophilic fasciitis. Extracutaneous manifestations and associations. Cutis 1984;34:259-61.

5 Kaklamanis $\mathbf{P}$, Vayopoulos G, Aroni K, Meletis J. Eosinophilic fasciitis with thrombocytopenia and Dupuytren's contracture. Scand J Rheumatol 1990; 19:245-7.

6 Kim H, Kim MO, Ahn M, Lee YY, Jung TJ, Choi IY, et al. Eosinophilic asciitis preceding relapse of peripheral T-cell lymphoma. J Korean Med Sci 2000; 15:346-50.

7 Naschitz JE, Yeshurun D, Miselevich I, Boss JH. Colitis and pericarditis in a patient with eosinophilic fasciitis. A contribution to the multisystem nature of eosinophilic fasciitis. J Rheumatol 1989;16:688-92.

8 Golner B, Furie R. Eosinophilic fasciitis associated with a monoclonal immunoglobulin [letter]. Clin Exp Rheumatol 1994;12:574.

9 Fuman EJ, Golbus J, Ike RW. Scleromyxedema with systemic involvement mimics rheumatic diseases. Arthritis Rheum 1986;29:913-17.

10 Oikarinem A, Ala- Kokko L, Palasti R, Peltonem L, Uitto J. Scleredema and paraproteinemia. Arch Dermatol 1987;123:226-9.

11 Ohta A, Uitto J, Oikarenen Al, Palasti R, Mitrane M, Bancila EA, et al. Paraproteinemia in patients with scleredema: clinical findings and serum effects on skin fibroblasts in vitro. J Am Acad Dermatol 1987; 16:96-107.

12 Kyle RA. Monoclonal gammopathy of undetermined significance. Natural history in 241 cases. Am J Med 1978;64:814-26.

13 Sato S, Hasegawa M, Takehara K. Serum levels of interleukin-6 and interleukin-10 correlate with total skin thickness score in patients with systemic sclerosis. J Dermatol Sci 200;27:140-6. 


\title{
Dust exposure: a missed environmental factor of Wegener's granulomatosis
}

\author{
B Granel, J Serratrice, P Disdier, S Abdul, R Gras, F Martin, L Swiader, P-J Weiller
}

Ann Rheum Dis 2002;61:1113

ex

nfectious agents, genetic background, and environmental exposure as observed in this case report, are thought to play a part in Wegener's granulomatosis (WG).

\section{CASE REPORT}

A 54 year old man consulted in 1999 for an eight year history of bilateral crusty and bloody rhinosinusitis. He had worked from 1965 to 1980 as a ship's carpenter. During this period he had constantly had nose pain, sore mucosal discomfort, frequent nasal bloody discharge, and chronic nasal obstruction when planing woods (iroko, oak, and ash), removing paint, and undertaking activities with dust exposure. He did not wear a mask. He had been a heavy smoker until the age of 40 and had never used cocaine. No nasal deformity was noted. Nasal fibroscopy disclosed erythematous and inflamed mucosa of the nasal septum and inferior turbinate in the left nasal cavity. There was biological inflammation with normal kidney function. A search for antinuclear and antiphospholipid antibodies was negative and serum angiotensin converting enzyme was normal. A high titre of antineutrophil cytoplasmic antibodies (ANCA) with cytoplasmic pattern on immunofluorescence and positivity of an enzyme linked immunosorbent assay (ELISA) for antiproteinase 3 antibodies ( $153 \mathrm{IU} / \mathrm{ml}$, normal <2) was noted. Blood lymphocyte immunophenotyping was normal. A thoracoabdominal computed tomographic (CT) scan was normal and a sinus CT scan showed evidence of thickening of the mucous membranes of the maxillar and frontal sinuses, associated with a bilateral ethmoiditis. Endonasal biopsy showed important granulomatous inflammation in the mucosa and around the vessel walls with necrosis compatible with WG.

The patient received oral steroids (40 $\mathrm{mg} /$ day) and trimethoprim-sulfamethoxazole in association with four intravenous cyclophosphamide pulses $\left(0.6 \mathrm{~g} / \mathrm{m}^{2}\right.$ every four weeks). One year later, the nasosinusal symptoms had almost completely regressed. The oral steroid dose was $18 \mathrm{mg} /$ day in association with trimethoprim-sulfamethoxazole. Control of the nasal fibroscopy and sinus CT scan were normal. A search for ANCA was negative.

\section{DISCUSSION}

In our patient, WG was diagnosed with chronic bilateral crusty and bloody rhinosinusitis, strong positivity of cANCA, and histopathological inflammatory infiltrate with necrosis. Moreover, the patient had been a ship carpenter with occupational exposure to irritating dusts and a long history of severe and bloody rhinitis at work.

Carpenters usually have an increased risk of chronic sinusitis, extrinsic allergic alveolitis, asthma, and sinus cancers. ${ }^{23}$ Neoplasms may occur up to 30 years after the end of exposure. Our patient had presented chronic rhinosinusitis when he was a ship's carpenter and 10 years later he presented recurrence of upper respiratory tract symptoms which led to the diagnosis of WG. A study of environmental exposure clearly showed that patients with WG had a significantly high exposure to fumes or particulate materials (chimney cleaning, carpet cleaning, plastering, and pesticides). ${ }^{4}$ Moreover, cases of WG in woodworkers were reported in the 1970s. ${ }^{56}$ The case described by Fombeur et al concerned a 23 year old man who had been a woodworker since the age of $18 .^{5}$ WG affected the sinuses, lungs, and kidney. ${ }^{5}$ Grimaud et al reported another case of sinonasal WG in a 34 year old carpenter. ${ }^{6}$ He presented necrotic pseudotumours in both sinuses associated with nasal septum perforation and ulceration of the soft palate. ${ }^{6}$ The fatal outcome was due to a pneumorenal syndrome. In their experience with 12 cases of WG, Israel and Patchefsky observed one case in a black woodworker. ${ }^{7}$

Neutrophils and cANCA seem to have an active role in the pathogenesis of WG. ${ }^{8}$ In our case, inflammatory response to irritative dusts might have induced a chronic rhinosinusitis and later favoured a cANCA related neutrophilic activation with a granulomatous reaction. Our observation reminds us that environmental exposure may constitute an underestimated triggering factor for WG. However, as woodworkers are rare nowadays, recent publications do not mention environmental exposure, which should nevertheless be taken into account

\section{Authors' affiliations}

B Granel, J Serratrice, P Disdier, L Swiader, P-J Weiller, Service de Médecine Interne, Hôpital de la Timone, 264 rue Saint-Pierre, 13385 Marseille Cedex 5, France

S Abdul, R Gras, Fédération d'Oto-Rhino-Laryngologie, Hôpital de la Timone

F Martin, Service de Médecine du Travail, Hôpital de la Timone

Correspondence to: Dr P Disdier; pdisdier@ap-hm.fr

Accepted 2 May 2002

\section{REFERENCES}

1 Gross WL, Trabandt A, Csernok E. Pathogenesis of Wegener's granulomatosis. Ann Med Interne 1998;149:280-6.

2 Luce D, Gérin M, Leclerc A, Morcet JF, Brugère J, Goldberg M Sinonasal cancer and occupational exposure to formaldehyde and other substances. Int J Cancer 1993:53:224-31.

3 Halpin DM, Graneek BJ, Lacey J, Nieuwenhuijsen M, Williamson PA, Venables KM, et al. Respiratory symptoms, immunological responses, and aeroallergen concentrations at a sawmill. Occup Environ Med 1994;51:165-72.

4 Duna GF, Cotch MF, Galperin C, Hoffman DB, Hoffman GS. Wegener's granulomatosis : role of environmental exposures. Clin Exp Rheumatol 1998; 16:669-74

5 Fombeur JP, Seguin D, Despres PH. Wegener's granulomatosis in a wood-worker. Ann Otolaryngol Chir Cervicofac 1974;91:417-25.

6 Grimaud R, Lapierre H, Labaeyre P, Jeannin C. Un cas de granulome malin de la face: Stewart ou Wegener? Ann Otolaryng (Paris) 1967;84:122-5

7 Israel HL, Patchefsky AS. Wegener's granulomatosis of lung: diagnosis and treatment. Experience with 12 cases. Ann Intern Med 1971;74:881-91.

8 Hewins P, Tervaet JW, Savage CO, Kallenberg CG. Is Wegener's granulomatosis an autoimmune disease? Curr Opin Rheumatol $2000 ; 12: 3-10$ 


\title{
Spinal cord stimulation in Buerger's disease
}

\author{
A V Pace, N Saratzis, D Karokis, D Dalainas, G D Kitas
}

B uerger's disease (BD) is characterised by segmental inflammation of medium and small size arteries, affects mainly young adult men, and is more prevalent in the southeast Mediterranean and the Far East. Its pathogenesis remains unclear, but cigarette smoking is strongly implicated. Autoimmune diseases, hypercoagulable states, diabetes, and emboli need exclusion before a diagnosis is made. The tibial and leg digital arteries are usually affected, and arteriography shows typically "corkscrew" peripheral obstructions. The best treatment is stopping smoking. Prostacyclin infusion is currently the most effective treatment for pain control and healing of ischaemic lesions. ${ }^{1}$ In selected cases, regional guanethidine block may have good results. ${ }^{2}$ Sympathectomy does not always provide longstanding benefit, ${ }^{3}$ and arterial bypass is difficult due to poor run-off in the diseased arteries. ${ }^{3}$ Limited amputations are often necessary to remove necrotic tissue.

New methods are being tested for pain relief and ulcer healing, including pedicled omental transfer ${ }^{5}$ and induction of angiogenesis using vascular endothelial growth factor gene transfer. ${ }^{6}$ Spinal cord stimulators (SCS) are used extensively in refractory peripheral atherosclerotic disease. Experience in BD is limited but suggests that SCS have favourable effects on pain and healing of digital ulcers, comparable with those noted in other arteriopathies. ${ }^{4}$

\section{CASE REPORTS}

We present our experience of the use of SCS in three patients with BD. They were all male, middle aged smokers, who had presented with painful ischaemic ulcers of the legs at least six years earlier, had typical angiographic appearances of BD, no evidence of other relevant diseases and had been (and still are) unable to stop smoking. Over that period, they had all required repeated admission to hospital and had unsuccessfully tried various treatments to relieve pain and promote healing of their ischaemic ulcers, including analgesics, vasodilators, antiplatelet agents, epidural analgesia, prostacyclin, and local guanethidine infusions. One patient had needed amputation of gangrenous toes and another a below-knee amputation after these treatments failed. SCS were used in all three patients to manage intractable pain, poor wound healing, and recurrence of ischaemic lesions occurring postoperatively. Within four months of treatment with SCS, the pain resolved completely and the wounds healed in all three patients and they were able to return to work. One of them requires oral analgesia after prolonged periods of standing, but none of them has required further admission to hospital.

\section{DISCUSSION}

SCS may modulate painful stimuli through several mechanisms. According to the gate control theory of pain, stimulation of large diameter, type A fibres at the posterior horns of the spinal cord by low amplitude electric current inhibits simultaneous transmission of painful stimuli through the same spinal cord segment. Similarly, inhibition of sympathetic vasoconstriction improves the peripheral microcirculation. Nitric oxide and $\gamma$-aminobutyric acid systems in the spinal cord may be important intermediaries in SCS-induced pain relief. ${ }^{78}$ In arterial insufficiency, SCS have been shown to decrease rest pain (Fontaine class III), improve claudication distance, raise skin temperature, and increase transcutaneous oxygen tension in the forefoot, with values of $>10 \mathrm{mmHg}$ before treatment being associated with significantly better outcome. ${ }^{910}$

SCS may be a useful therapeutic option in BD, particularly for pain control and wound healing and may delay the need for amputation in selected patients who have exhausted all other therapeutic options. Return to work and reduced need for repeated hospital admissions may balance the overall expense of the procedure. Further studies are required to determine the exact indications for the use of SCS in BD, while stopping smoking should continue to be emphasised as the most important treatment.

\section{Authors' affiliations}

A V Pace, D Karokis, G D Kitas, Department of Rheumatology, Dudley Group of Hospitals NHS Trust, UK

N Saratzis, D Dalainas, 1 st Department of Surgery, AHEPA University Hospital, Thessaloniki, Greece

Correspondence to: Dr G D Kitas, Department of Rheumatology, Dudley Group of Hospitals NHS Trust, The Guest Hospital, Tipton Road, Dudley, West Midlands DY1 4SE, UK; g.d.kitas@bham.ac.uk

Accepted 16 April 2002

\section{REFERENCES}

1 Fiessinger JN, Scafer M. Trial of iloprost versus aspirin treatment for critical limb ischaemia of thromboangiitis obliterans. Lancet 1990;335:555-7

2 Stumpflen A, Ahmadi A, Attender A, Gschwandtner M, Hofmann S Maca T, et al. Effects of transvenous regional guanethidine block in the treatment of critical finger ischaemia. Angiology 2000;51:115-22.

3 Sayin A, Bozhurt AK, Tuzun H, Vural FS, Erdog G, Ozer M. Surgical treatment of Buerger's disease. Experience with 216 patients. Cardiovasc Surg 1993; 1:377-80

4 Swigris JJ, Olin JW, Mekhail NA. Implantable spinal cord stimulator to treat the ischaemic manifestations of thromboangiitis obliterans (Buerger's disease) J Vasc Surg 1999:29:928-35.

5 Talwar S, Jain S, Porwal R, Laddha BL, Prasad P. Pedicled omental transfer for limb salvage in Buerger's disease. Int J Cardiol 2000;72:127-32

6 Isner JM, Baumgartner I, Rauh G, Schainfeld R, Blair R, Manor O, et al. Treatment of thromboangiitis obliterans (Buerger's disease) by intramuscular gene transfer of vascular endothelial growth factor: preliminary clinical results. J Vasc Surg 1998;38:964-73

7 Croom JE, Foreman RD, Chandler M, Koss MC, Barron KW. Role of nitric oxide in cutaneous blood flow increase in the rat hindpaw during dorsal cord stimulation. Neurosurgery 1997;40:565-70.

8 Stanton-Hicks $M$, Salamon J. Stimulation of the central and peripheral nervous system for the control of pain. J Clin Neurophysiol 1997; 14:46-62.

9 Ghajar AW, Miles JB. The differential effect of the level of spinal cord stimulation on patients with advanced peripheral vascular disease in the lower limbs. Br J Neurosurg 1998;12:402-8.

10 Claeys LG, Horsch S. Transcutaneous oxygen pressure as predictive parameter for ulcer healing in endstage vascular patients treated with spinal cord stimulation. Int Angiol 1996;15:344-9. 